\title{
O Impacto das Metodologias Ativas no Ensino e Aprendizagem nas Ciências Contábeis Segundo a Percepção Docente
}

\begin{abstract}
Patrícia Pereira Castro ${ }^{1}$
'Departamento de Ciências Contábeis Universidade Estadual de Mato Grosso do Sul, Brasil | ctcastro@globo.com | https://orcid.org/0000-0002-6490-1559

Resumo: Evidências bibliográficas sugerem que as metodologias ativas trouxeram contribuições positivas para o processo de ensino-aprendizagem, assim, pode-se inferir que, as metodologias ativas trouxeram mudanças que se relacionam com as premissas das diretrizes curriculares nacionais para o curso de Graduação em Ciências Contábeis. Neste contexto, este artigo estuda o efeito das metodologias ativas nas competências e habilidades concebidas no decorrer dos primeiros semestres do curso de Ciências Contábeis, na percepção docente. $O$ trabalho foi direcionado a sete docentes, dos dois primeiros semestres, do curso de Ciências Contábeis, de uma instituição de Ensino Superior da capital sul-matogrossense que implantou as Metodologias Ativas em seus cursos, em 2019. Realizou-se a entrevista, através de um questionário com dezessete questões, incluindo questões fechadas para parametrização da amostra e discursivas sobre o objetivo de estudo. A análise do conteúdo das entrevistas permitiu categorizar os resultados de forma quantitativa e qualitativa. Constatou-se que, $85,7 \%$ dos entrevistados atuam na docência há mais de 6 anos e que todos utilizam os métodos ativos há pelo menos 1 ano (a maioria entre 2 a 5 anos) e na maioria de suas disciplinas, e um percentual significativo percebeu diversas habilidades e competências desenvolvidas pelos alunos por meio da utilização das Metodologias Ativas. As metodologias mais utilizadas entre os entrevistados são a "sala de aula invertida" e "aprendizagem baseada em problemas". Conclui-se que, na percepção dos entrevistados as metodologias ativas aumentaram o desenvolvimento das competências e habilidades dos alunos do curso de Ciências Contábeis. Além disso, na percepção da maioria dos docentes entrevistados as metodologias ativas comparada a metodologia tradicional facilitaram o processo de aprendizagem dos alunos.
\end{abstract}

Palavras-chave: Metodologia de Ensino; Aprendizagem; Competências e Habilidades.

The Impact of Active Methodologies on Teaching and Learning in Accounting Sciences According to Teaching Perception

\begin{abstract}
Bibliographic evidence suggests that active methodologies brought positive contributions to the teaching-learning process, thus, it can be inferred that, active methodologies brought changes that are related to the premises of national curricular guidelines for the Undergraduate course in Accounting. In this context, this article studies the effect of active methodologies on the competences and skills conceived during the first semesters of the Accounting course, in the teaching perception. The work was directed to seven teachers, from the first two semesters of the Accounting Sciences course, from a Higher Education institution in the capital of Mato Grosso do Sul that implemented Active Methodologies in their courses in 2019. The interview was held, through a questionnaire with seventeen questions, including closed questions for parameterization of the sample and discursive about the objective of the study. The analysis of the content of the interviews allowed to categorize the results in a quantitative and qualitative way. It was found that $85.7 \%$ of respondents have been teaching for more than 6 years and that everyone has been using active methods for at least 1 year (mostly between 2 and 5 years) and in most of their disciplines, and a percentage significant perceived several skills and competences developed by students through the use of Active Methodologies. The most used methodologies among the interviewees are the "inverted classroom" and "problem-based learning". It is concluded that, in the interviewees' perception, the active methodologies increased the development of the competences and skills of the students of the Accounting course. In addition, in the perception of most of the teachers interviewed, the active methodologies compared to the traditional methodology facilitated the students' learning process.
\end{abstract}

Keywords: Teaching Methodology; Learning; Skills and Abilities. 


\section{Introdução}

O presente trabalho tem por objetivo identificar o efeito das metodologias ativas nas competências e habilidades desenvolvidas no decorrer dos primeiros semestres do curso de Ciências Contábeis, na percepção docente. Apurar se um novo método de ensino teoricamente superior de fato trouxe reflexos positivos na prática é de suma importância na discussão para a escolha da metodologia a ser aplicada no decorrer do ensinoaprendizagem.

Evidências bibliográficas sugerem que as metodologias ativas trouxeram contribuições positivas para o processo de ensino-aprendizagem (Morata et al., 2011; Fernández et al., 2014; Ferreira et al, 2017; Azevedo et al., 2019). Assim, pode-se inferir que, as metodologias ativas trouxeram mudanças que se relacionam com as premissas das diretrizes curriculares nacionais para o curso de Graduação em Ciências Contábeis.

Morata et al. (2011) apresentaram as experiências de um grupo de professores e indicaram que metodologias, como resolução de casos e trabalho colaborativo trouxeram excelentes resultados, pois envolveu os alunos em seu próprio processo de ensinoaprendizagem. Fernández et al. (2014) concluíram que o uso das metodologias ativas permite ao corpo docente universitário desenvolver um trabalho mais racional com os alunos.

Azevedo et al., (2019) analisaram a percepção docente e dentre as diversas constatações identificaram que $69 \%$ dos participantes utilizam os métodos ativos entre 2 a 5 anos, e um percentual significativo percebeu que as metodologias facilitam 0 processo de aprendizagem dos alunos. Ferreira et al. (2017) apontaram que segundo a percepção dos alunos, as metodologias de ensino que melhor contribuem para o processo de ensino aprendizagem, "são: aulas práticas, pois assim o aluno ligará a teoria com a prática, aulas expositivas com diálogo entre professor e aluno, seminários, debate e trabalhos em grupos foram os mais citados".

Ressalta-se que, em várias pesquisas e bibliografias, as metodologias ativas são aplicadas para explorar o ensino-aprendizagem de um modo amplo (Bacich \& Moran, 2017; Tajra, 2019; Spanhol et al., 2018; Feferbaum \& Klafke, 2020). Nas Ciências Contábeis, há estudos que examinaram estratégias específicas ou a aplicabilidade da metodologia ativa em determinada disciplina, por exemplo: o uso de competição em sala de aula, comparativo entre o ensino tradicional e a aplicação da aprendizagem baseada em problemas, a eficácia dos videogames, os impactos das metodologias ativas no desempenho dos discentes (Breton, 1999; Stanley \& Marsden, 2012; Gainor et al., 2014; Carenys et al., 2017).

Sendo assim, observa-que, os estudos existentes examinaram o efeito da aplicabilidade das metodologias ativas de forma ampla ou experimentais em IES cujo modelo é tradicional, porém, este trabalho visa apresentar o efeito das metodologias ativas no desenvolvimento de competências e habilidades em alunos de uma instituição cuja metodologia é $100 \%$ ativa.

Tal investigação se justifica em virtude das mudanças ocorridas no cenário educacional e a necessidade constante de adaptabilidade das instituições de ensino para atenderem os futuros egressos e empregadores.

Optou-se pelo curso de Ciências Contábeis, pois é uma profissão necessária mundialmente, atualmente, há $354.879^{1}$ contadores com registro ativo no Brasil e nas duas edições do Exame de Suficiência ${ }^{2}$, de 2019, 69.332 egressos fizeram as provas e destes somente 23.787 foram aprovados. E, segundo, Breda (2020) "esses números são sintomáticos de um sistema de ensino superior que precisa de melhorias".

\footnotetext{
${ }^{1}$ Disponível em: https://cfc.org.br/registro/quantos-somos-2/

2 Requisito para a obtenção de registro profissional em Conselho Regional de Contabilidade. (Lei n.ำ $12.249 / 2010)$
} 
Verifica-se, neste trabalho que, em geral, na percepção dos docentes entrevistados as metodologias ativas aumentaram o desenvolvimento das competências e habilidades dos alunos do curso de Ciências Contábeis e que se, aplicada a metodologia tradicional, os estudantes não desenvolveriam as mesmas competências e habilidades.

Espera-se, com este trabalho contribuir com a literatura acadêmica e o mercado da profissão contábil sobre: a) o efeito das metodologias ativas no ensino do curso de Ciências Contábeis, b) habilidades e competências adquiridas pelos alunos do curso de Ciências Contábeis e c) a metodologia mais adequada ao ensino-aprendizagem das ciências contábeis.

\section{Competências e Habilidades Esperadas dos Egressos de Ciências Contábeis}

Todo curso superior, no Brasil, "depende de autorização do Ministério da Educação" exceto as universidades e centros universitários, conforme Decreto № 5.773 (2006).

Para a abertura do curso de Ciências Contábeis é preciso elaborar um Projeto Pedagógico de acordo com as Diretrizes Curriculares Nacionais para o Curso de Graduação em Ciências Contábeis, bacharelado, conforme Resolução CNE/CES no 10 (2004).

O Ministério da Educação estabelece um perfil mínimo para os futuros egressos e o art. 3, da Resolução CNE/CES no 10 (2004) estabelece as capacidades mínimas a serem desenvolvidas no curso de graduação em Ciências Contábeis. Além disso, a referida Resolução estabelece ainda competências e habilidades mínimas a serem desenvolvidas.

Com o advento do Decreto-Lei n. .07 .988 (1945) ficou estabelecido o tempo de duração do curso e as disciplinas mínimas, para o curso de Ciências Contábeis. Contudo, o referido Decreto não trata das competências e habilidades a serem desenvolvidas nos egressos. Entrementes, se compararmos o conteúdo do referido decreto com Diretrizes Curriculares Nacionais podemos observar uma semelhança, alternando basicamente a ordem.

A Fundação Brasileira de Contabilidade, considerando que "a Ciência Contábil exige constante atualização e agregação de novos conhecimentos", propôs, em 2017 uma matriz curricular para os cursos de Ciências Contábeis com o objetivo de melhorar as matrizes curriculares das IES e consequentemente trazer à tona as competências e habilidades mínimas estabelecidas pelo Ministério da Educação (Carneiro et al., 2017, 2017).

\subsection{Metodologias Ativas}

$\mathrm{Na}$ educação superior, as instituições de ensino, independentemente de seu modelo, estão buscando cada vez se adaptar a necessidade de evolução, além das mudanças provocadas pelo avanço tecnológico, a alteração social, que resulta em um novo perfil de estudante com expectativas diversificadas (Biggs, 1999; Álvarez et al., 2013; Morata et al., 2011; Gómez et al., 2013). Inserido nesse processo há o professor, um dos responsáveis pela formação do egresso, que precisa rever seu posicionamento frente esse momento, 0 qual requer capacitação e alteração nas metodologias de ensino utilizadas. 
E dentre as alterações das metodologias de ensino utilizadas, temos nas Metodologias Ativas "a inserção do aluno como agente protagonista de seu processo de construção do conhecimento" e que "o professor precisou assumir o papel de orientador de estudos" (Malheiros, 2019). E ainda, de acordo com Malheiros (2019), as principais características das metodologias ativas de aprendizagem são: "professor como orientador", "aluno como protagonista", "relação de parceria entre professor e aluno", "estímulo à autonomia intelectual do aluno", "foco do processo no desenvolvimento de habilidades mentais", "uso de desafios como caminho para a aprendizagem", e "princípio de que o verdadeiro aprendizado surge da prática."

Temos que as "metodologias ativas são estratégias de ensino centradas na participação efetiva dos estudantes na construção do processo de aprendizagem, de forma flexível, interligada e híbrida" (Bacich \& Moran, 2018).

Segundo del Castillo (2018) as metodologias ativas envolvem efetivamente o aluno na realização de atividades que estimulem sua aprendizagem, com ênfase no reconhecimento e na exploração das competências e habilidades, sistema de valores, processos mentais, maneira de pensar e capacidade de se expressar. Ainda neste contexto, Gainor et al. (2014), sugerem que a abordagem de aprendizagem ativa é eficaz por três razões principais: i) concentra-se no próprio aluno e os alunos facilmente relacionar com os exemplos criados por seus pares; ii) capacita os alunos; e iii) cria um ambiente competitivo de aprendizagem ativa.

\subsection{Desenvolvimento de Hipóteses}

As instituições de ensino superior são responsáveis pela geração e exploração de conhecimento e formação de profissionais diferenciados capazes de integrar teoria e prática. De acordo com Sacristán et al. (2011), as competências podem capacitar para demandas complexas, mais próximas de situações reais.

Sendo assim, um dos principais "desafios da educação é definir uma metodologia pedagógica que permita a transmissão de competências de forma transversal e holística" (López-Alcarria et al., 2019). Neste contexto, Mazzarol et al. (2016) afirmam que as instituições de ensino fornecem aos graduados conhecimentos e habilidades e o SENAC (2018) destaca que "as metodologias ativas são consideradas essenciais para viabilizar o desenvolvimento efetivo das competências".

Desta forma, para que os alunos sejam altamente eficazes em competências e habilidades estabelecidas nas diretrizes nacional do MEC são importantes e necessária sala de aula de projetos, atividades que deem sentido à teoria (López, 2018), metodologias estas qualificadas como ativas e, evidências bibliográficas anteriores sugerem que as metodologias ativas têm efeito positivo no ensino-aprendizagem.

Diante disto, pergunta-se: as metodologias ativas aumentaram o desenvolvimento das competências e habilidades dos alunos do curso de Ciências Contábeis?

Para responder à questão de pesquisa, a seguinte hipótese foi desenvolvida: As metodologias ativas aumentaram o desenvolvimento das competências e habilidades dos alunos do curso de Ciências Contábeis. 


\section{Metodologia}

Trata-se de uma pesquisa exploratória ${ }^{3}$, descritiva ${ }^{4}$ e analítica ${ }^{5}$, com abordagens quantitativa ${ }^{6}$ e qualitativa ${ }^{7}$. A coleta de dados foi uma documentação direta ${ }^{8}$ por meio de uma entrevista com 7 (sete) docentes. Todos os docentes exercem alguma atividade em um currículo com métodos ativos de ensino-aprendizagem e vivenciaram os impactos da mudança curricular, pois todos atuam na docência há mais de 4 (quatro) anos.

Realizou-se a entrevista, através de um questionário com dezessete questões, incluindo questões fechadas para parametrização da amostra e discursivas sobre o objetivo de estudo. O link para responder o questionário foi enviado via whatsapp para 7 (sete) docentes dos dois primeiros semestres, do curso de Ciências Contábeis, de uma instituição de ensino superior da capital sul-mato-grossense que implantou as Metodologias Ativas em seus cursos, em 2019, atingindo todos.

Realizou-se uma análise indutiva, sem categorias anteriores orientando a codificação, por meio de coleta; leitura, decomposição, a fim de identificar as unidades de significado relevantes; organização e enumeração através de um processo de codificação aberto, axial e seletivo; e síntese e resumo de dados para a divulgação dos resultados.

\section{Resultados}

Esta pesquisa foi direcionada aos docentes dos dois primeiros semestres, do curso de Ciências Contábeis, de uma Faculdade da capital sul-mato-grossense que implantou as Metodologias Ativas em seus cursos, em 2019, respondendo dessa forma à questão colocada como problema de pesquisa se "as metodologias ativas aumentaram o desenvolvimento das competências e habilidades dos alunos do curso de Ciências Contábeis". Os resultados foram codificados conforme Tabela 1.

Tabela 1. Participantes

\begin{tabular}{lllllll}
\hline ID & Gênero & Faixa etária & Maior Titulação & $\begin{array}{c}\text { Tempo de } \\
\text { experiência na } \\
\text { docência }\end{array}$ & $\begin{array}{c}\text { Docência é } \\
\text { Principal } \\
\text { Atividade }\end{array}$ & $\begin{array}{c}\text { Atuação em } \\
\text { mais de uma } \\
\text { IES }\end{array}$ \\
\hline E1 & Feminino & 36 a 40 anos & Mestrado & Acima de 6 anos & sim & sim \\
E2 & Feminino & 36 a 40 anos & Especialização & Acima de 6 anos & não & não \\
E3 & Masculino & 27 a 30 anos & Mestrado & Acima de 6 anos & sim & sim \\
E4 & Feminino & Acima de 40 anos & Mestrado & Acima de 6 anos & sim & sim
\end{tabular}

3 “Exploratória: se o autor tem como objetivo tornar mais explícito o problema, aprofundar as ideias sobre o objeto de estudo. Este tipo de pesquisa permite o levantamento bibliográfico e o uso de entrevistas com pessoas que já tiveram experiência acerca do objeto a ser investigado." (Alves, 2006)

4 "Descritiva: descreve as características de uma população ou de um fenômeno, ou ainda estabelece relações entre fenômenos (variáveis). Adota- se como procedimento a coleta de dados, com uso da entrevista e da observação, e como recursos, os questionários e/ou formulários, entre outros. É muito usada nas pesquisas de levantamento." (Alves, 2006)

5 "Envolve o estudo e a avaliação, em profundidade, das informações disponíveis na tentativa de explicar fenômenos complexos. Os diferentes tipos de pesquisa analítica são: histórico, filosófico, de revisão e de síntese de pesquisas." (Thomas et al., 2012)

6 "[quantitative research] I. Modalidade de pesquisa na qual variáveis predeterminadas são mensuradas e expressas numericamente. Os resultados também são analisados com o uso preponderante de métodos quantitativos (ex.: estatística); II. Modalidade de pesquisa que investiga fatos (ver contraposição em pesquisa qualitativa). V.tb.: pesquisa e pesquisa qualitativa." (Apolinário, 2011)

7 "[qualitative research] Modalidade de pesquisa na qual os dados são coletados através de interações sociais (p. ex.: estudos etnográficos e pesquisas participantes) e analisados subjetivamente pelo pesquisador; II. Enquanto a pesquisa quantitativa investiga fatos, a pesquisa qualitativa preocupa-se com fenômenos, sendo que um fato é tudo o que pode ser objetivamente observado e definido por consenso social, enquanto um fenômeno remete-nos à interpretação de um fato feita por um observador. Ou seja, o fenômeno é a interpretação subjetiva do fato. V.tb.: pesquisa e pesquisa quantitativa." (Apolinário, 2011)

8 "Se vale das observações e das entrevistas" (Alves, 2006) 


\begin{tabular}{|c|c|c|c|c|c|c|}
\hline ID & Gênero & Faixa etária & Maior Titulação & $\begin{array}{l}\text { Tempo de } \\
\text { experiência na } \\
\text { docência }\end{array}$ & $\begin{array}{l}\text { Docência é } \\
\text { Principal } \\
\text { Atividade }\end{array}$ & $\begin{array}{c}\text { Atuação em } \\
\text { mais de uma } \\
\text { IES }\end{array}$ \\
\hline E5 & Masculino & 36 a 40 anos & Mestrado & Acima de 6 anos & não & não \\
\hline E6 & Masculino & Acima de 40 anos & Doutorado & Acima de 6 anos & não & $\operatorname{sim}$ \\
\hline E7 & Feminino & 36 a 40 anos & Mestrado & 4 a 6 anos & não & não \\
\hline
\end{tabular}

A amostra utilizada nesta pesquisa englobou 7 (sete) docentes, sendo a maioria mulheres $(57,14 \%)$. Sobre o corpo docente, a Lei de Diretrizes e Bases para a Educação Nacional - LDB no 9.394/96 (1996), destaca que para o ensino superior deverá ser composto de "um terço, pelo menos, com titulação acadêmica de mestrado ou doutorado". Sendo assim, verificou-se a maior titulação dos entrevistados, apurando que 14,3\% são especialistas, $71,4 \%$ são mestres e 14,3\% são doutores.

O resultado da pesquisa, apresentou que $85,7 \%$ dos docentes entrevistados atuam na docência há mais de 6 anos e o restante, 14,3\% atuam na docência entre 4 a 6 anos. Identificando que $42,9 \%$ tem a docência como sua principal atividade e que, $57,1 \%$ trabalha em mais de uma Instituição de Ensino Superior.

Mediu-se a liberdade de escolha dos entrevistados para a escolha da metodologia a ser utilizada em sala de aula, constatando que a maioria, $57,1 \%$ obrigatoriamente deve utilizar as Metodologias Ativas e o restante, $42,9 \%$ por estar dentro do grupo que trabalha em mais de uma IES informou que em uma(s) utiliza(m) as Metodologias Ativas e outra(s) somente a metodologia tradicional. Sendo que $42,9 \%$ utilizam as Metodologias Ativas há 1 ano, $42,9 \%$ há 2 anos e $14,3 \%$ há mais de 3 anos.

Após identificar há quanto tempo os entrevistados se utilizam das Metodologias Ativas, verificou-se o nível de utilização da referida metodologia, apurando que $28,6 \%$ dos entrevistados utilizam as Metodologias Ativas na minoria das disciplinas, por outro lado $28,6 \%$ utilizam na maioria das disciplinas e o restante, $42,9 \%$ utilizam em $100 \%$ de suas disciplinas.

Além disso, os resultados, apresentaram que a metodologia ativa "sala de aula invertida" é utilizada por $100 \%$ dos entrevistados e depois a "aprendizagem baseada em problemas" e "aprendizagem por pares", conforme Figura 1.

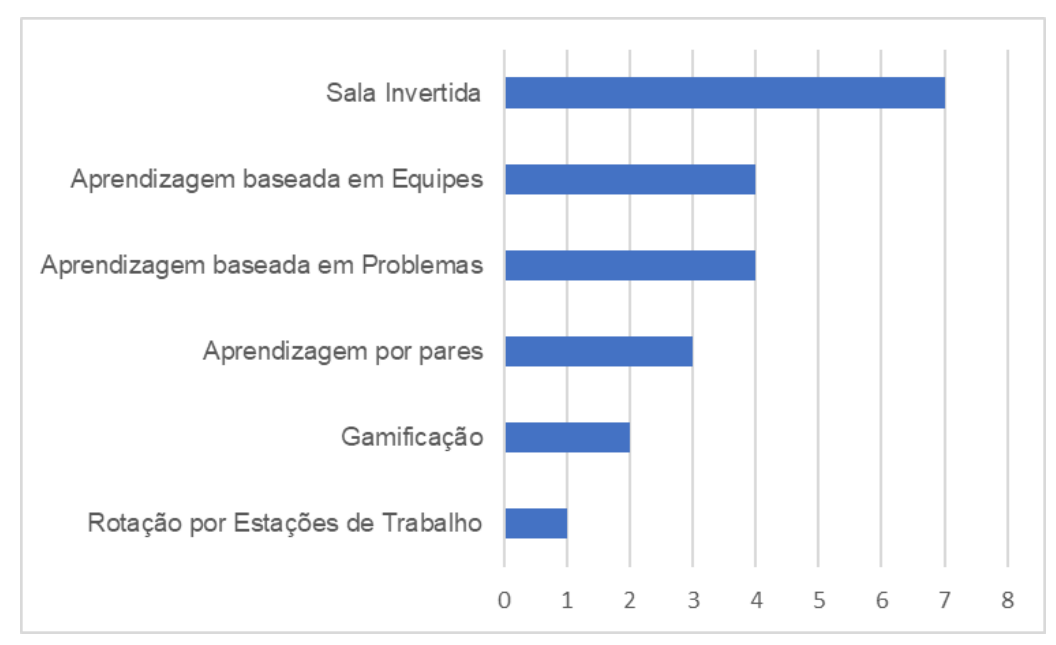

Fig. 1. Metodologias Ativas mais utilizadas

Considerando o processo de desenvolvimento docente para atuar em currículos que utilizam métodos ativos de ensino-aprendizagem, cinco dos entrevistados apontaram duas dificuldades em comum: i) "baixos salários, tendo em vista o tempo necessário para preparação da aula" e ii) "falta de tempo para preparar as aulas, pois demanda um tempo maior que a metodologia tradicional" e outros apontaram "Insegurança na aplicação da nova metodologia", conforme Figura 2. Considerando este cenário, estratégias ativas consomem um tempo maior para implementação (Stanley \& Marsden, 2012). 


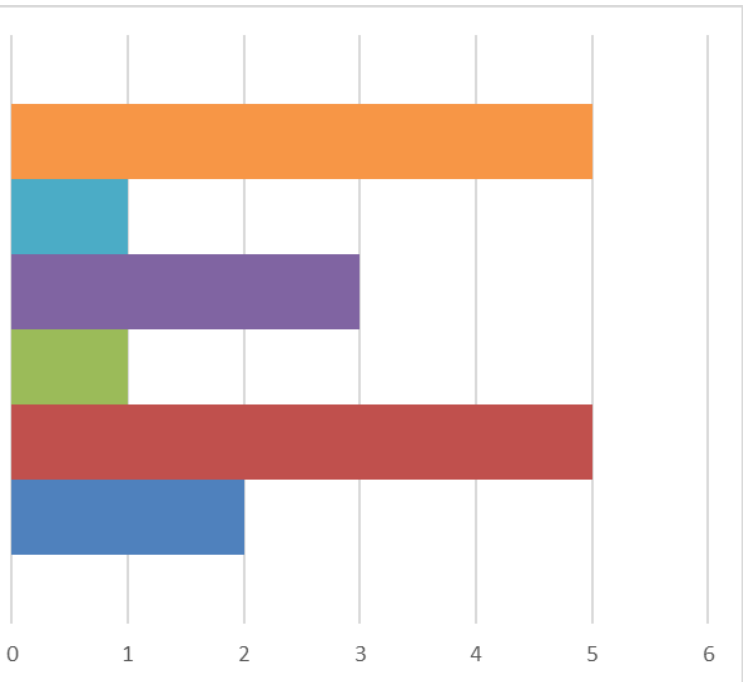

Fig. 2. Metodologias Ativas mais utilizadas

Almeida \& Batista (2011) apresentaram que dentre as dificuldades encontradas "há ênfase na desvalorização do professor, com a institucionalização da docência caracterizada pelo pouco reconhecimento, baixos salários e, consequentemente, falta de tempo".

Os docentes entrevistados conceituaram as metodologias ativas em 8,6 (oito pontos e seis décimos), quando comparada as metodologias tradicionais. Neste contexto (Breton, 1999), concluiu que os métodos de aprendizagem baseados em problemas produzem melhores resultados e sugere que os alunos submetidos ao $\mathrm{PBL}$ estão conscientes de ter adquirido algum conhecimento e habilidade, bem como, esperam ser mais úteis a longo prazo.

Segue abaixo, Figura 3, a qual apresenta as competências e habilidades desenvolvidas pelos alunos do curso de ciências contábeis quando da utilização das Metodologias Ativas, na percepção dos entrevistados, algumas extraídas e estabelecidas na Resolução CNE/CES $n ¹ 0$. Vale salientar que a pesquisa se refere aos alunos dos dois primeiros semestres.

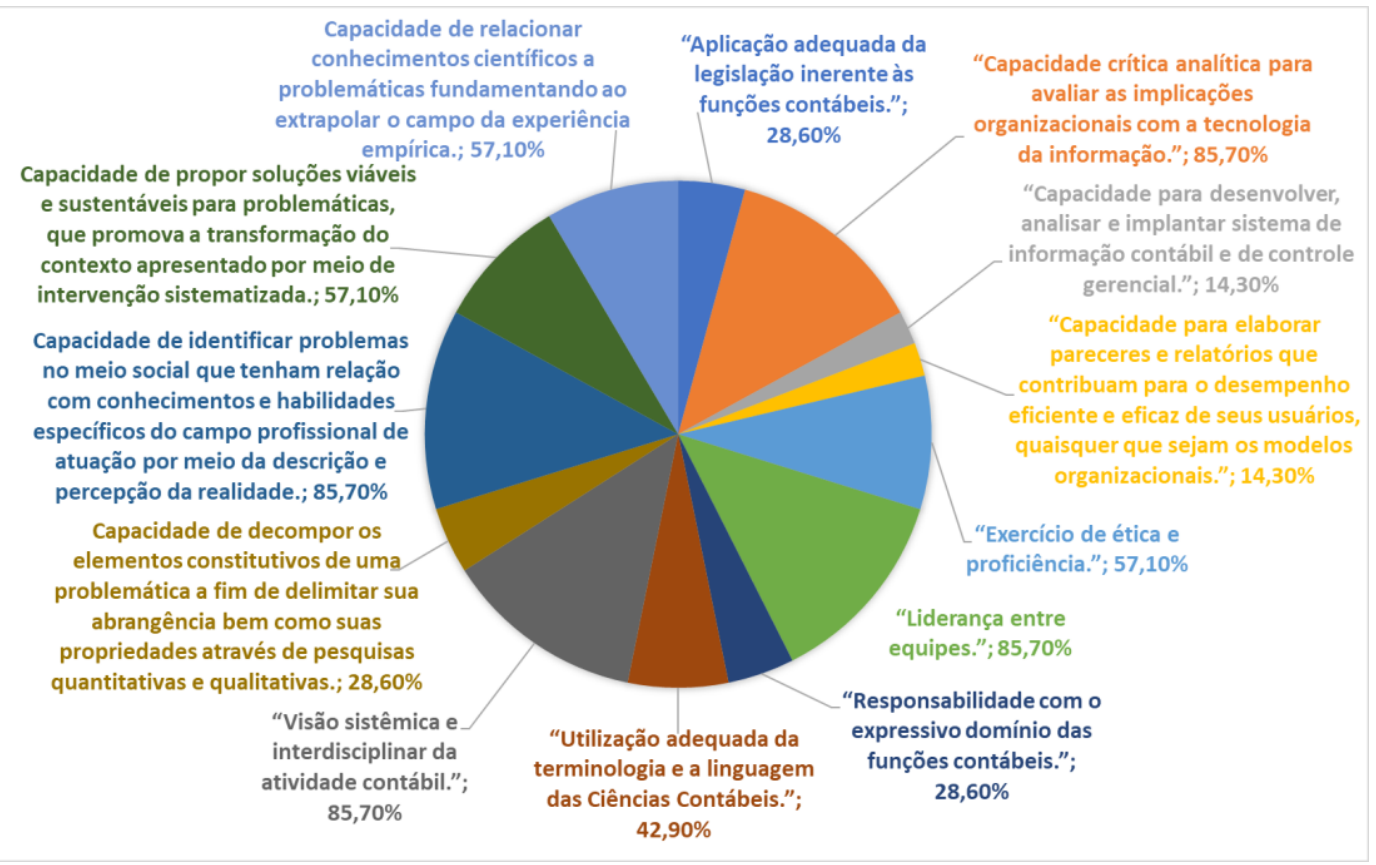

Fig. 3. Habilidades desenvolvidas pelos estudantes com o uso das Metodologias Ativas conforme a percepção dos entrevistados 
Ao questionar os entrevistados "se, aplicada a metodologia tradicional, os estudantes também desenvolveriam as mesmas competências e habilidades supracitadas" constatouse que a maioria acredita que não $(71,43 \%)$. Neste contexto, Nagib \& da Silva (2019) constataram que "para promover a construção do conhecimento técnico-teórico alinhado com o desenvolvimento das habilidades nos estudantes, surgiram métodos de ensino aprendizagem que superam a metodologia tradicional" e destacam as metodologias ativas. Contudo, o mesmo estudo revelou que "a adoção de metodologias ativas pode se tornar um diferencial para determinadas disciplinas, enquanto para outras, não".

De acordo com a percepção de todos os entrevistados, as metodologias ativas aumentaram o desenvolvimento das competências e habilidades dos alunos do curso de graduação de Ciências Contábeis, conforme as justificativas abaixo:
"A prática está em todos os níveis e semestres isso desenvolve responsabilidade crítica nos estudantes" (E2).
"Faz com que consigam fazer link entre a teoria e a prática" (E6).
"Nas metodologias ativas, o centro da aprendizagem é o estudante, respeitando suas particularidades e promovendo a autonomia e o protagonismo estudantil" (E4).
"O aluno aprende mais na prática e vivendo casos reais limpando a teoria com a prática" (E5).
"Promove o pensamento crítico dos estudantes" (E7).

De acordo com a percepção de todos os entrevistados, as metodologias ativas são superiores à metodologia tradicional para o estudante absorver conhecimentos básicos, técnicos, profissionais e complementares, fundamentados na construção e articulação entre a teoria e a prática, conforme as justificativas abaixo:
"Os alunos possuem acesso a uma diversidade de informações, mas nem sempre conseguem contextualizá-las de maneira correta. Assim, cabe ao docente atuar mais como mediador da aprendizagem, orientando os acadêmicos a aplicar essas informações no contexto apropriado, aliando a teoria à prática necessária no mercado de trabalho e na vida cotidiana" (E4). "O aluno se torna protagonista da sua história" (E5).
"O estudante sai da passividade da aula tradicional e assume os estudos, preparando para debates e discussões" (E6).
"Potencializa a aprendizagem significativa dos estudantes" (E7).

Diante dos resultados encontrados, apresenta-se a conclusão deste estudo.

\section{Conclusões}

Este trabalho analisou se o uso das metodologias ativas no ensino-aprendizagem desenvolveu competências e habilidades nos alunos dos primeiros semestres do curso de Ciências Contábeis de forma superior a metodologia tradicional, na percepção docente. Apurou-se que a metodologia teoricamente superior, de fato, trouxe reflexos positivos no ensino-aprendizagem dos alunos, conforme evidências bibliográficas.

Para viabilizar a realização desta pesquisa, coletaram-se dados provenientes de uma entrevista com sete docentes dos dois primeiros semestres, do curso de Ciências Contábeis, de uma instituição de Ensino superior da capital sul-mato-grossense que implantou as Metodologias Ativas em seus cursos, em 2019. Constatou-se que, 85,7\% dos entrevistados atuam na docência há mais de 6 anos e que todos utilizam os métodos ativos há pelo menos 1 ano (a maioria entre 2 a 5 anos), e um percentual significativo percebeu diversas habilidades e competências desenvolvidas pelos alunos por meio da utilização das Metodologias Ativas.

De acordo com $85,7 \%$ dos entrevistados, dentre as habilidades e competências mínimas a serem desenvolvidas no decorrer da graduação de Ciências Contábeis em conformidade com a diretriz nacional do curso estão: i) a "capacidade crítica analítica para avaliar as implicações organizações com a tecnologia da informação"; ii) "liderança de equipes"; iii) 
"visão sistêmica e interdisciplinar da atividade contábil" e $57,1 \%$ percebeu que os alunos desenvolveram o "exercício de ética e proficiência".

Destaca-se que foram analisados apenas os dois primeiros semestres do curso de Ciências Contábeis e já se observou competências e habilidades que deveriam ser desenvolvidas durante os quatro anos de curso. Na percepção dos docentes entrevistados se, aplicada a metodologia tradicional, os estudantes não desenvolveriam as mesmas competências e habilidades supracitadas e comparando as metodologias ativas com as metodologias tradicionais, os entrevistados conceituaram a metodologia ativa com 8,6.

Isto se daria, em síntese, porque as metodologias ativas desenvolvem a responsabilidade e pensamento crítico dos alunos e os mesmos aprendem mais com a vivência. Além, disso perceberam que a utilização das metodologias ativas torna o aluno o protagonista de sua história, o preparando adequadamente para debates e discussões. Potencializando significativamente a aprendizagem dos alunos.

Para finalizar, os resultados deste artigo criam perspectivas para novas pesquisas. A pesquisa futura deve comparar os resultados deste trabalho examinando as competências e habilidades desenvolvidas nos alunos de outras instituições de ensino, bem como uma análise da evolução do ensino-aprendizagem dos alunos da instituição ora estudada ao longo do curso por exemplo, um comparativo entre a evolução anual do ensinoaprendizagem verificando inclusive se a possibilidade de alcance de todas as competências e habilidades desejadas na diretriz nacional para o curso de ciências contábeis, antes mesmo do término do curso. Sugere-se ainda, pesquisa junto aos empregadores destes discentes para determinar se as competências e habilidades desenvolvidas se traduziram na força de trabalho.

\section{Referências}

Almeida, M. T. C., \& Batista, N. A. (2011). Ser docente em métodos ativos de ensinoaprendizagem na formação do médico. Revista Brasileira de Educação Médica, 35(4), 468476. https://doi.org/10.1590/s0100-55022011000400005

Álvarez, M. L., Fidalgo, R., Arias-Gundín, O., \& Robledo, P. (2013). La Eficacia De Las Metodologías Activas En El Rendimiento Del Alumnado De Magisterio. Journal of Chemical Information and Modeling, 53(9), 1689-1699.

Alves, M. (2006). Como Escrever Teses e Monografias [recurso eletrônico] (Grupo GEN (org.)).

Apolinário, F. (2011). Dicionário de metodologia científica: um guia para a produção do conhecimento científico [recurso eletrônico] (Grupo GEN (org.); 2a edição).

Azevedo, S. B., Pacheco, V. A., \& Santos, E. A. dos. (2019). Metodologias ativas no ensino superior: percepção de docentes em uma instituição privada do Distrito Federal. Revista Docência do Ensino Superior, 9, 1-22. https://doi.org/10.35699/2237-5864.2019.2573

Bacich, L., \& Moran, J. (2018). Metodologias Ativas para uma Educação Inovadora [recurso eletrônico] (Penso (org.)).

Biggs, J. (1999). What the student does: Teaching for enhanced learning. Higher Education Research and Development, 18(1), 57-75. https://doi.org/10.1080/07294360.2012.642839

Brasil. (1945). Decreto-Lei n.o 7.988 de 22 de setembro de 1945. Dispõe sobre o ensino superior de ciências econômicas e de ciências contábeis e atuariais. Diário Oficial da União, 26 set. 1945. https://www2.camara.leg.br/legin/fed/declei/1940-1949/decreto-lei-7988-22-setembro1945-417334-norma-pe.html

Brasil. (1996). Lei no 9.394 de 20 de dezembro de 1996. Estabelece as diretrizes e bases da educação nacional. Diário Oficial da União, 23 dez. 1996. http://www.planalto.gov.br/ccivil_03/Leis/L9394.htm

Brasil. (2006). Decreto no 5.773 de 9 de maio 2006. Dispõe sobre o exercício das funções de regulação, supervisão e avaliação de instituições de educação superior e cursos superiores de graduação e sequenciais no sistema federal de ensino. Diário Oficial da União. http://www.planalto.gov.br/ccivil_03/_ato2004-2006/2006/decreto/d5773.htm

Breda, Z. I. (2020). Ponte para o Futuro. https://cfc.org.br/destaque/artigo-ponte-para-o-futuro/

Breton, G. (1999). Some empirical evidence on the superiority of the problem-based learning (PBL) method. International Journal of Phytoremediation, 21(1), 1-12. https://doi.org/10.1080/096392899331008 
Carenys, J., Moya, S., \& Perramon, J. (2017). Is it worth it to consider videogames in accounting education? A comparison of a simulation and a videogame in attributes, motivation and learning outcomes. Revista de Contabilidad-Spanish Accounting Review, 20(2), 118-130. https://doi.org/10.1016/j.rcsar.2016.07.003

Carneiro, J. D., Rodrigues, A. T. L., Silva, A. C. R. da, França, J. A. de, Almeida, J. E. F. de, \& Morais, M. L. S. de. (2017). Matriz Curricular para Cursos de Ciências Contábeis. In Fundação Brasileira de Contabilidade.

CNE, C. N. de E. (2004). Resolução CNE/CES no 10, de 16 de dezembro de 2004. Institui as Diretrizes Curriculares Nacionais para o Curso de Graduação em Ciências Contábeis, bacharelado, e dá outras providências. Diário Oficial da União, Seção 1(28/12/2004), 15. http://portal.mec.gov.br/cne/arquivos/pdf/rces10_04.pdf

del Castillo, M. J. L. (2018). Origen y desarrollo de las metodologías activas dentro del sistema educativo español. Encuentro. Revista del Departamento de Filología Moderna, 27, 4-21. http://www3.uah.es/encuentrojournal/index.php/encuentro/article/download/2/2

Feferbaum, M., \& Klafke, G. F. (2020). Metodologias Ativas em Direito [recurso eletrônico] (Grupo GEN (org.)).

Fernández, N. G., Ruiz, R. G., Liaño, S. G., \& Arregui, E. Á. (2014). Metodologías activas en la docencia universitaria: importancia, conocimiento y uso en opinion del profesorado. Revalue, 2(2). http://ojs.inee.edu.mx/revista/index.php/revalue/article/view/69

Ferreira, S., Almeida, J. B. De, \& Araújo, W. G. (2017). Métodos de Ensino Aplicados no Curso de Ciências Contábeis : percepção de alunos da Universidade Federal do Tocantins ( UFT ). 1, 763-772.

Gainor, M. E., Bline, D., \& Zheng, X. (2014). Teaching internal control through active learning. Journal of Accounting Education, 32(2), 200-221. https://doi.org/10.1016/j.jaccedu.2014.03.003

Gómez, Hu. S., Peláez, A. D., Arias, J. D. B., \& Ramos, C. E. P. (2013). Metodologías Activas Del Aprendizaje (Fundación Universitaria María Cano (org.)).

López-Alcarria, A., Olivares-Vicente, A., \& Poza-Vilches, F. (2019). A systematic review of the use of Agile methodologies in education to foster sustainability competencies. Sustainability (Switzerland), 11(10), 1-30. https://doi.org/10.3390/su11102915

López, J. L. O. (2018). Scrum Como Estrategia Para El Aprendizaje Colaborativo a Través De Proyectos. Propuesta Didáctica Para Su Implementación En El Aula Universitaria. Profesorado, Revista de Currículum y Formación del Profesorado, 22(2). https://doi.org/10.30827/profesorado.v22i2.7735

Malheiros, B. T. (2019). Didática Geral. Didática geral [recurso eletrônico] (LTC (org.); 2a Edição).

Mazzarol, T., Battisti, M., \& Clark, D. (2016). The role of universities as catalysts within entrepreneurial ecosystems. In book: Rhetoric and reality: Building vibrant and sustainable entrepreneurial ecosystems, 36-68.

Morata, F. S., Rodríguez, C. I., Iranzo, R. G., \& Jordana, R. R. (2011). Metodologías activas en la docencia universitaria: resultados de algunas experiencias realizadas. IX Jornades de xarxes d'investigació en docència universitària [Recurso electrónico]: Disseny de bones pràctiques docents en el context actual, 81 pp. http://rua.ua.es/dspace/handle/10045/19885

Nagib, L. de R. C., \& da Silva, D. M. (2019). Adoption of active methodologies and their relationship with the life cycle and the qualifications of teaching staff in undergraduate courses in accounting. Revista Contabilidade e Financas, 31(82), 145-164. https://doi.org/10.1590/1808-057x201909030

Sacristán, J. G. et al. (2011). Educar por competências: o que há de novo [recurso eletrônico] (Artmed (org.)).

SENAC. Departamento Nacional. (2018). Metodologias ativas de aprendizagem [recurso eletrônico] (D. N. Senac (org.)).

Spanhol, F. J., Farias, G. F. de, \& Souza, M. V. de. (2018). EAD, PBL e desafio da educação em rede: metodologias ativas e outras práticas na formação do educador coinvestigador [recurso eletrônico] (Blucher (org.)).

Stanley, T., \& Marsden, S. (2012). Problem-based learning: Does accounting education need it? Journal of Accounting Education, 30(3-4), 267-289. https://doi.org/10.1016/j.jaccedu.2012.08.005

Tajra, S. F. (2019). Informática na Educação: O Uso de Tecnologias Digitais na Aplicação das Metodologias Ativas [recurso eletrônico] (Érica (org.); 10a Ed.).

Thomas, J. R., Nelson, J. K., \& Silverman, S. J. (2012). Métodos de Pesquisa em Atividade Física [recurso eletrônico] (Editora Artmed (org.); 6a Ed.). 